\title{
Sickle Cell Disease-Induced Pulmonary Hypertension: A Review of Pathophysiology, Management, and Current Literature
}

\author{
Abu Baker Sheikh ${ }^{a} \quad$ Adeel Nasrullah $^{b}$ Erick Daniel Lopez ${ }^{a}$ Mian Tanveer Ud Din ${ }^{b}$ \\ Shazib Sagheer ${ }^{c}$ Ishan Shah ${ }^{a}$ Nismat Javed $^{d}$ Rahul Shekhar $^{\mathrm{e}}$ \\ aDepartment of Internal Medicine, University of New Mexico Health Sciences Center, Albuquerque, NM, USA; \\ ${ }^{b}$ Department of Internal Medicine, Allegheny Health Network, Pittsburgh, PA, USA; 'Division of Cardiology, University \\ of New Mexico Health Sciences Center, Albuquerque, NM, USA; ${ }^{d}$ Shifa College of Medicine, Shifa Tameer-e-Millat \\ University, Islamabad, Pakistan; 'Division of Hospital Medicine, Department of Internal Medicine, University of New \\ Mexico School of Medicine, Albuquerque, NM, USA
}

\section{Keywords}

Sickle cell disease · Pulmonary hypertension ·

Pathophysiology · Management · Diagnosis

\begin{abstract}
Sickle cell disease is an inherited hemoglobinopathy leading to the synthesis of hemoglobin S. Hemoglobin S results in the formation of abnormal sickle-shaped erythrocytes that lead to hematologic abnormalities such as hemolytic anemia and increased risks of thrombosis. Another particular problem encountered with the disease is pulmonary hypertension. The objective of this narrative review is to discuss the prevalence, pathophysiology mechanisms, diagnostic techniques, treatment options, and prognostic indicators in the setting of sickle cell disease with pulmonary hypertension. Additionally, the review also highlights other advancements that are being investigated. Considering the significant morbidity, mortality, and prevalence of pulmonary hypertension in patients with sickle cell disease, it is important to account for the aforementioned domains in the future
\end{abstract}

guidelines to provide optimal and individualized care to the high-risk individuals as well as reduce the progression of disease, morbidity, and mortality rates.

(c) 2021 S. Karger AG, Basel

\section{Introduction}

Sickle cell disease (SCD) is defined as an inherited hemoglobinopathy associated with chronic hemolytic anemia with characteristic findings of sickle-shaped erythrocytes caused by homozygous inheritance of hemoglobin $\mathrm{S}(\mathrm{HbS})$ as defined by the American Society of Hematology [1]. SCD is associated with World Health Organization (WHO) Group 5 pulmonary hypertension $(\mathrm{PH})$ which is defined as a resting mean pulmonary arterial pressure $(\mathrm{PAP}) \geq 25 \mathrm{~mm} \mathrm{Hg}$ on invasive testing as stated by the American Thoracic Society [2]. A variety of pathologic processes can result in $\mathrm{PH}$ in SCD patients as illustrated in Figure 1 [3]. karger@karger.com www.karger.com/pls
(C) 2021 S. Karger AG, Basel

Karger"
Correspondence to:

Abu Baker Sheikh, absheikh@salud.unm.edu 
Fig. 1. Various pathophysiological processes that can lead to PH in SCD are depicted.

Fig. 2. Summary of hemodynamic measures in different subtypes of SCD-related $\mathrm{PH}$. $\mathrm{PH}$, pulmonary hypertension
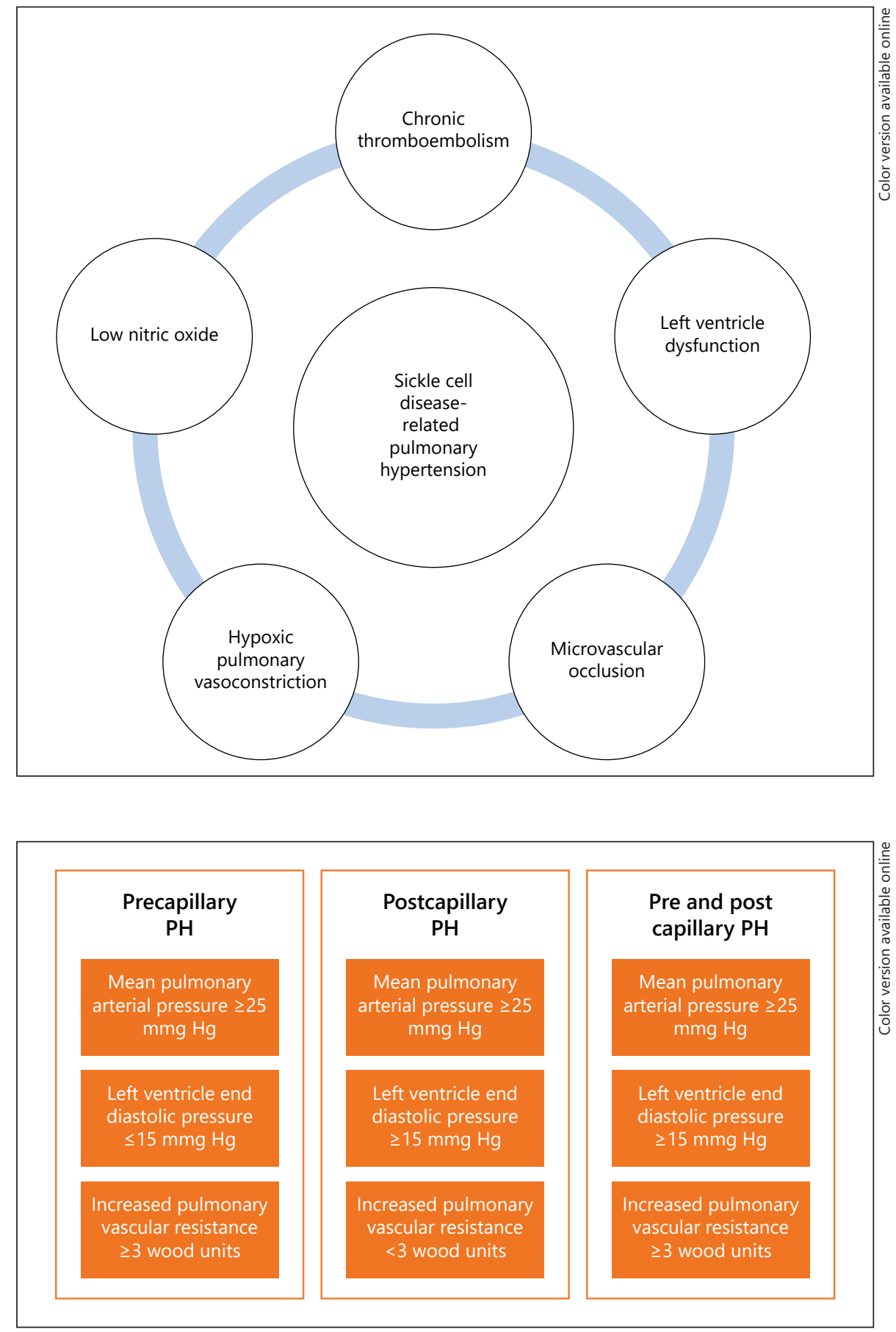

Due to the multifaceted mechanisms involved, SCD can result in both precapillary and postcapillary $\mathrm{PH}$ with almost equal distribution reported in the population [2]. Right heart catheterization (RHC) is the gold standard test to diagnose $\mathrm{PH}$ and describe its subtypes. Different patterns of hemodynamics in each phenotype of SCDrelated $\mathrm{PH}$ are illustrated in Figure 2 [4].
$\mathrm{PH}$ in the setting of SCD increases mortality regardless of the severity of $\mathrm{PH}[2,5]$. Hydroxyurea is one such intervention that has been associated with reduced mortality compared to untreated patients with SCD [6]. Despite these interventions, particular attention should be directed toward screening this patient population to implement timely treatment.
58

Pulse 2021;9:57-63

DOI: $10.1159 / 000519101$
Sheikh/Nasrullah/Lopez/Tanveer Ud Din/ Sagheer/Shah/Javed/Shekhar 
Table 1. Hemolysis-related mechanisms in PH in SCD patients

\begin{tabular}{|c|c|}
\hline eDAMPs & $\begin{array}{l}\text { Released during massive tissue injury associated with activation of innate immunity pathways via the toll-like receptors and the } \\
\text { nucleotide-binding oligomerization domain-like receptors of the inflammasome leading to persistent intravascular hemolysis in } \\
\mathrm{PH}\end{array}$ \\
\hline Arginase 1 & $\begin{array}{l}\text { Increased levels are seen in hemolytic activity. Its function consists of metabolizing L-arginine to ornithine, thereby reducing } \\
\text { levels of L-Arginine. L-Arginine is required for de novo nitric oxide synthesis by eNOS enzyme; thereby, reductions of L-arginine } \\
\text { lead to lower arginine: ornithine ratios. Increased ornithine levels are associated with smooth muscle cell proliferation, } \\
\text { peribronchial, and perivascular collagen deposition. This is associated with the increased severity of PH and mortality }[9,10]\end{array}$ \\
\hline $\begin{array}{l}\text { ADMA and } \\
\text { hyperhomocysteinemia }\end{array}$ & $\begin{array}{l}\text { Endogenous NOS inhibitor hydrolyzed by DDAH. Associated with hyperhomocysteinemia as homocysteine can inhibit DDAH } \\
\text { activity leading to elevated plasma ADMA levels and decreased NO production. NO deficits have been associated with PH in } \\
\text { SCD patients }\end{array}$ \\
\hline $\begin{array}{l}\text { ROS (xanthine oxidase, } \\
N A D P H, S O D s \text { ) }\end{array}$ & $\begin{array}{l}\text { Generated during intravascular hemolysis. Can form ROS causing endothelial dysfunction activating downstream oxidases } \\
\text { promoting vascular oxidative stress. Lower levels of SOD are seen in SCD due to higher tricuspid regurgitant velocity, thereby } \\
\text { leading to increased oxidative stress [11] }\end{array}$ \\
\hline
\end{tabular}

\section{Prevalence and Epidemiology}

According to the Centers for Disease Control \& Prevention, SCD affects estimated 100,000 Americans. Centers for Disease Control \& Prevention also reports that each year approximately 300,000 new cases of infants worldwide will be born with SCD with a risk of the rate of incidence increasing to $30 \%$ more by 2050 [7]. It is highly prevalent in African American populations with every 1 in 500 African American carrying an autosomal recessive mutation [8]. An estimated $10-33 \%$ of patients with SCD are found to have PH on screening by adulthood, and up to $75 \%$ of patients with SCD have findings of $\mathrm{PH}$ seen on autopsies according to the Pulmonary Hypertension Association [2]. SCD-related PH confers 2-5\% mortality to this subset of patients [8].

\section{Pathophysiology}

SCD results from point mutations or deletions in the beta-globin gene leading to the production of $\mathrm{HbS}$. The severity of the disease varies depending on different genotypes of SCD, though it is directly proportional to the degree of production of HbS. Sickling of red blood cells results in multiorgan microvascular occlusion and intravascular hemolysis, releasing free hemoglobin $(\mathrm{Hgb})$ and arginase in the circulation leading to deoxygenated states.

Sickle Cell Disease-Induced Pulmonary Hypertension
The pathophysiology behind SCD and PH is considered to be multifactorial as there are multiple mechanisms proposed in the literature. Hemolytic anemia contributes to chronic organ injury and has been associated with $\mathrm{PH}$ in SCD patients. Breakdown of erythrocytes leading to disseminated intracellular pro-inflammatory molecules such as erythrocyte danger-associated molecular patterns (eDAMPs), adenosine deaminase (ADA), purine nucleoside phosphorylase (PNP), arginase 1 , asymmetric dimethylarginine (ADMA), and ROS (xanthine oxidase, nicotinamide adenine dinucleotide phosphate [NADPH], superoxide dismutases [SODs]) has been associated in SCD patients with $\mathrm{PH}$ [3]. Other mechanisms excluding hemolysis have also been linked in SCD patients with $\mathrm{PH}$. These include upregulation of placental growth factor (PlGF) in response to hemolysis with subsequent elevated levels of endothelin-1 (ET-1), loss of peroxisome proliferator-activated receptor $\mathrm{y}$ (PPARY), hyperhomocysteinemia, decreased availability of nitric oxide leading to elevated vascular cell adhesion molecule 1 (VCAM-1), intercellular adhesion molecule 1 (ICAM-1), E-selectin, phosphatidylserine, plasma protein thorombospondin-1 (TSP-1), decreased levels of Apo-A1, Factor-FX complex, asplenia, and polymorphisms in transforming growth factor (TGF) (Table 1 [3, 9-11], and online suppl. material 1; for all online suppl. material, see www.karger.com/ doi/10.1159/000519101 [12,13]). Among these important pathways, arginase 1 and eDAMPs are being actively investigated because these molecules aim at reducing sterile 
inflammation and oxidative stress [14]. Animal-based models have suggested that ADA and PNP can accelerate the development of $\mathrm{PH}$ by eliminating the protective effects of adenosine, inosine, and glutamine [15]. Similarly, arginase inhibition can increase levels of nitric oxide leading to an attenuated systemic and pulmonary vascular endothelial dysfunction [16]. Although not directly involved, decreased levels of NADPH can alter intracellular erythrocyte redox environment, resulting in sickling and remodeling that might contribute to $\mathrm{PH}$ [17].

\section{Diagnosis}

As per American Thoracic Society Clinical Practice Guidelines of 2014, RHC is the gold standard for diagnosing $\mathrm{PH}$ in SCD. The use of imaging modalities such as transthoracic echocardiograms can be beneficial in clinical practice and, however, does not offer a definitive diagnosis [18]. Other useful laboratory tests include N-terminal prohormone brain natriuretic peptide levels $\geq 160 \mathrm{pg} / \mathrm{mL}$, elevated $\mathrm{LDH}$ above $475 \mathrm{U} / \mathrm{L}$, reticulocyte counts above $300,000 \mathrm{cells} / \mathrm{mm}^{3}$, serum ferritin levels above $1,000 \mathrm{ng} /$ $\mathrm{mL}$, and elevated serum creatinine concentration above 1 $\mathrm{mg} / \mathrm{dL}$ for severe sickling phenotypes, above $1.4 \mathrm{mg} / \mathrm{dL}$ for mild sickling phenotypes $[3,19]$. Recently, the use of Growth Differentiation Factor-15 (GDF-15) which is a multifactorial cytokine expressed in cardiomyocytes, vascular smooth muscle cells, and endothelial cells is strongly upregulated in response to oxidative stress, inflammation, and tissue injury in SCD and has been investigated as a potential biomarker for $\mathrm{PH}$ in SCD patients [20]. Another potential biomarker that is currently being investigated is the use of superoxide dismutase 2, which is a major mitochondrial antioxidant enzyme associated with hemolysis, oxidative stress, and SCD PH and cardiomyopathy which has been found to have decreased expression in SCD patients with $\mathrm{PH}$ [11]. Although future investigations might improve modalities available for diagnosing $\mathrm{PH}$ in SCD, RHC remains the gold standard diagnostic modality [2].

\section{Management}

The proposed strategy for $\mathrm{PH}$ in patients with SCD involves SCD-specific therapy including hydroxyurea and/or chronic packed red blood cell transfusion in combination with medications approved for $\mathrm{PH}$. There are no established guidelines for the management of $\mathrm{PH}$ in SCD due to inadequate evidence in this patient population.
Moreover, due to the complexity of these patients, it is recommended that they are referred to $\mathrm{PH}$ centers for better outcomes [21].

\section{Sickle Cell Anemia Directed Therapy}

Both hydroxyurea and chronic packed red blood cell transfusions reduce $\mathrm{HbS}$ in the blood and prevent sickling, which has been known to contribute to the pathogenesis of $\mathrm{PH}$ in patients with sickle cell anemia (SCA). Hydroxyurea is preferred as first-line therapy due to its safer profile compared to chronic transfusions which are associated with multiple adverse effects including allergic reactions, iron overload, alloimmunization, and volume overload [22]. Guidelines from the American Thoracic Society strongly recommend the use of hydroxyurea as first-line therapy in all SCD patients with increased mortality risk, which is defined as a tricuspid regurgitation velocity $\geq 2.5 \mathrm{~m} / \mathrm{s}$, an NTpro-BNP level $\geq 160 \mathrm{pg} / \mathrm{mL}$, or RHC-confirmed $\mathrm{PH}$ [18]. The mechanism of action of hydroxyurea involves the increased synthesis of fetal $\mathrm{Hgb}$ which decreases vaso-occlusive episodes and hence ameliorates the clinical course of SCA [23]. However, the beneficial effects of hydroxyurea do not manifest until several months after initiation. A randomized controlled trial followed patients taking hydroxyurea for 17.5 years to examine the risk and benefit of longterm use. The trial showed that $47.5 \%$ of deaths in patients with SCA were due to pulmonary complications and $87.5 \%$ of these deaths were attributed to patients who never took hydroxyurea or used it for $<5$ years [24].

The American Thoracic Society recommends chronic transfusion therapy in patients that have an increased mortality risk and are unresponsive to hydroxyurea [18]. However, unlike hydroxyurea, there are no clinical trials as yet to support the use of chronic transfusions for $\mathrm{PH}$ in patients with SCD [25]. Chronic transfusion therapy is known to reduce strokes and acute coronary syndrome in patients with SCA and hypothetically should slow down the progression of $\mathrm{PH}$ by preventing clot formation in the pulmonary vasculature. To effectively prevent vaso-occlusive episodes, the goal of the exchange transfusion is to maintain $\mathrm{HbS}$ at $<30$ percent of total $\mathrm{Hgb}$ and total $\mathrm{Hgb}$ of $>9 \mathrm{~g} / \mathrm{dL}$. HbS, Hgb, and reticulocyte counts are monitored with every transfusion to follow the trend and schedule subsequent transfusion [26]. Serum ferritin levels must be obtained every 1-3 months to prevent iron overload. Generally, both hydroxyurea and chronic transfusions are not administered simultaneously, as chronic transfusions can reduce the efficacy of hydroxyurea [21].
Sheikh/Nasrullah/Lopez/Tanveer Ud Din/ Sagheer/Shah/Javed/Shekhar 
Another treatment strategy that is often adopted in patients with SCA is long-term anticoagulation. SCA, despite being a pro-thrombotic state, has also been known to increase the risk of intracerebral and retinal hemorrhage. Acute therapy for venous thromboembolism is recommended. However, due to the paucity of evidence regarding risk and benefit, long-term anticoagulation remains controversial. Guidelines recommend indefinite anticoagulant therapy for patients with SCD with RHC-confirmed $\mathrm{PH}$, only if they have a history of venous thromboembolism and no additional risk factors for hemorrhage [18].

\section{Pulmonary Arterial Hypertension Directed Therapy}

Finally, in select patients, targeted pulmonary arterial hypertension (PAH) therapy can be used. This usually includes endothelin receptor antagonists, phosphodiesterase- 5 inhibitors, prostacyclin agonists, and guanylate cyclase stimulators (e.g., riociguat). However, in patients with concomitant SCA and PAH, phosphodiesterase- 5 inhibitors are strongly discouraged due to adverse side effects that were first noticed in the Pulmonary Hypertension and Sickle Cell Disease with Sildenafil Therapy (WalkPHaSST) clinical trial [27]. The study was terminated due to an increase in serious adverse events in the sildenafil group, primarily hospitalization for a pain crisis. For symptomatic patients with elevated pulmonary vascular resistance confirmed with RHC and normal pulmonary artery wedge pressure, a trial of endothelin receptor antagonists (Ambrisentan) and prostacyclin agonists (Epoprostenol and Treprostinil) can be considered [22]. The trials for these medications had some limitations. However, due to their established benefit in group $1 \mathrm{PAH}$ patients and 4 case series of SCA patients showing positive results, the medications are recommended in the abovementioned patients [28]. The recommendation, nonetheless, remains weak because of the low quality of evidence [22]. Soluble guanylate cyclase stimulators have not been studied in SCD and have properties similar to phosphodiesterase-5 inhibitor therapy; hence, their use remains uncertain.

\section{Prognosis}

$\mathrm{PH}$ and an elevated tricuspid regurgitant jet velocity are important prognostic factors for SCD patients. Tricuspid regurgitant jet velocity of at least $2.5 \mathrm{~m} / \mathrm{s}$ is associated with an increased risk of death (rate ratio, 10.1; 95 percent confidence interval [CI], 2.2-47.0; $p<0.001$ ) compared with a velocity of $<2.5 \mathrm{~m} / \mathrm{s}$ [29]. In a longitudinal study, a total of 529 adults with SCD were screened by echocardiography between 2001 and 2010. After a 9-year follow-up, the following hemodynamic variables were associated with increased mortality: mean PAP (hazard ratio [HR], 1.61 ; 95\% CI, $1.05-2.45$ per $10 \mathrm{~mm} \mathrm{Hg}$ increase; $p=0.027)$, diastolic PAP (HR, 1.83; 95\% CI, 1.09-3.08 per $10 \mathrm{~mm} \mathrm{Hg}$ increase; $p=0.022$ ), diastolic PAP - pulmonary capillary wedge pressure (HR, 2.19; 95\% CI, $1.23-$ 3.89 per $10 \mathrm{~mm} \mathrm{Hg}$ increase; $p=0.008)$, transpulmonary gradient (HR, 1.78; 95\% CI, 1.14-2.79 per $10 \mathrm{~mm} \mathrm{Hg}$ increase; $p=0.011$ ), and pulmonary vascular resistance (HR, 1.44; 95\% CI, $1.09-1.89$ per wood unit increase; $p=$ 0.009 ) as risk factors for mortality [30].

\section{Future Advancements}

A multidisciplinary approach which involves the development of care pathways to educate the patients regarding their disease and mitigate various risk factors associated with $\mathrm{PH}$ is integral to better survival. Prompt identification and management of hypoxemia, venous thromboembolism, severe anemia, iron overload, restrictive lung disease, and LV diastolic dysfunction may prevent the development of $\mathrm{PH}$ [5]. Markers such as lactate dehydrogenase, indirect bilirubin, elevated ferritin, NTproBNP, and forced expiratory volume in $1 \mathrm{~s}$ to vital capacity ratio $<80$ are associated with the development of $\mathrm{PH}$. Hence, risk stratification models incorporating these variables should be devised and strategies to prolong RBC survival may decrease the risk of $\mathrm{PH}$ in SCD [31]. Hydroxycarbamide prolongs RBC survival, decreases endothelial dysfunction, and increases $\mathrm{HbF}$; hence, its roles in the prevention of $\mathrm{PH}$ should be investigated in prospective studies [6]. Cardiac MRI can identify early diastolic dysfunction and myocardial fibrosis; hence, its applicability should be standardized early in the course of the disease [2]. Anemia in SCD-related PH is associated with increased mortality and exchange transfusion results in improvement of anemia. However, the mortality benefit of exchange transfusions in SCD-related $\mathrm{PH}$ needs to be studied in longitudinal studies [3]. Automated red cell exchange recently did show promising results in the reduction of symptoms of $\mathrm{PH}$ and improved echocardiographic parameters in SCD-related $\mathrm{PH}$ [32]. It utilizes an apheresis system to replace patient's red cells with donor cells resulting in a rapid reduction of $\mathrm{HbS}$. Further studies should investigate its role in the long-term reduction of morbidity and mortality in SCD-related PH. 


\section{Conclusion}

$\mathrm{PH}$ is a common complication in patients with SCD. Considering the prevalence of the problem, there is an emerging need to develop targeted therapy to combat the proposed mechanisms in place. The management of these patients requires a multidisciplinary care team to ensure that the vicious cycle of disease exacerbation can be broken. However, all these aspects necessitate further studies that target specific management options, combine specialty approaches, and, possibly, predict the impact of these changes in mortality and morbidity rates. The endgame is to utilize all the information from future clinical studies in a concise practice guideline for future management. Furthermore, early screening should be considered with laboratory investigations, echocardiography, and RHC when needed, to initiate aggressive treatment to delay the disease progression and reduce the mortality from $\mathrm{PH}$.

\section{Acknowledgments}

The authors have no acknowledgments to declare.

\section{Conflict of Interest}

The authors have no conflict of interest to declare.

\section{Funding Sources}

The authors have no funding to declare.

\section{Author Contributions}

A.S., A.N., E.D.L., M.T., S.S., and I.S. were responsible for the study concept and design; A.S., A.N., E.D.L., M.T., S.S., I.S., N.J., and R.S. drafted the literature review; A.N. wrote the initial draft; S.S. revised the draft and proofread; R.S. and S.S. proofread; A.S. and A.N. provided images; R.S. presented resources; N.J. performed formatting; R.S. and S.S. involved in supervision.

\section{References}

1 DeBaun MR, Jordan LC, King AA, Schatz J, Vichinsky E, Fox CK, et al. American Society of Hematology 2020 guidelines for sickle cell disease: prevention, diagnosis, and treatment of cerebrovascular disease in children and adults. Blood Adv. 2020 Apr;4(8):1554-88.

2 Wood KC, Gladwin MT, Straub AC. Sickle cell disease: at the crossroads of pulmonary hypertension and diastolic heart failure. Heart. 2020 Apr;106(8):562-8.

3 Gordeuk VR, Castro OL, Machado RF. Pathophysiology and treatment of pulmonary hypertension in sickle cell disease. Blood. 2016 Feb;127(7):820-8.

4 Hayes MM, Vedamurthy A, George G, Dweik R, Klings ES, Machado RF, et al. Pulmonary hypertension in sickle cell disease. Ann Am Thorac Soc. 2014 Nov; 11(9):1488-9.

5 Rees DC, Williams TN, Gladwin MT. Sicklecell disease. Lancet. 2010 Dec;376(9757): 2018-31.

6 Ataga KI, Moore CG, Jones S, Olajide O, Strayhorn D, Hinderliter A, et al. Pulmonary hypertension in patients with sickle cell disease: a longitudinal study. Br J Haematol. 2006 Jul;134(1):109-15.

7 Sedrak A, Kondamudi NP. Sickle cell disease. Florida: StatPearls Publishing; 2021.

8 Pecker LH, Lanzkron S. Sickle cell disease. Ann Intern Med. 2021 Jan;174(1):ITC1-16.

9 Kato GJ, Steinberg MH, Gladwin MT. Intravascular hemolysis and the pathophysiology of sickle cell disease. J Clin Invest. 2017 Mar; 127(3):750-60.

10 Savale L, Humbert M, Klings ES. Pulmonary hypertension in sickle cell disease: current controversies and clinical practices. In: Ford
HJ, Heresi GA, Risbano MG, editors. Pulmonary hypertension. New York: Humana Press; 2020. p. 123-34.

11 Armenis I, Kalotychou V, Tzanetea R, Moyssakis I, Anastasopoulou D, Pantos C, et al. Reduced peripheral blood superoxide dismutase 2 expression in sickle cell disease. Ann Hematol. 2019 Jul;98(7):1561-72.

12 Yasin Z, Witting S, Palascak MB, Joiner $\mathrm{CH}$, Rucknagel DL, Franco RS. Phosphatidylserine externalization in sickle red blood cells: associations with cell age, density, and hemoglobin F. Blood. 2003 Jul;102(1):365-70.

13 Kennedy JR. Attenuating a sickle cell crisis with annexin V. Med Hypotheses. 2015 May; 84(5):434-6.

14 Bean CJ, Boulet SL, Ellingsen D, Pyle ME, Barron-Casella EA, Casella JF, et al. Heme oxygenase-1 gene promoter polymorphism is associated with reduced incidence of acute chest syndrome among children with sickle cell disease. Blood. 2012 Nov; 120(18):3822-8.

15 Bilan VP, Schneider F, Novelli EM, Kelley EE, Shiva S, Gladwin MT, et al. Experimental intravascular hemolysis induces hemodynamic and pathological pulmonary hypertension: association with accelerated purine metabolism. Pulm Circ. 2018 Jul-Sep; 8(3): 2045894018791557.

16 Steppan J, Tran HT, Bead VR, Oh YJ, Sikka G, Bivalacqua TJ, et al. Arginase inhibition reverses endothelial dysfunction, pulmonary hypertension, and vascular stiffness in transgenic sickle cell mice. Anesth Analg. 2016 Sep; 123(3):652-8

17 Morris CR, Suh JH, Hagar W, Larkin S, Bland DA, Steinberg MH, et al. Erythrocyte glutamine depletion, altered redox environment, and pulmonary hypertension in sickle cell disease. Blood. 2008 Jan;111(1):40210.

18 Klings ES, Machado RF, Barst RJ, Morris CR Mubarak KK, Gordeuk VR, et al. An official American Thoracic Society clinical practice guideline: diagnosis, risk stratification, and management of pulmonary hypertension of sickle cell disease. Am J Respir Crit Care Med. 2014 Mar;189(6):727-40.

19 Liem RI, Lanzkron S, D Coates T, DeCastro L, Desai AA, Ataga KI, et al. American Society of Hematology 2019 guidelines for sickle cell disease: cardiopulmonary and kidney disease. Blood Adv. 2019 Dec;3(23):3867-97.

20 Larissi K, Politou M, Margeli A, Poziopoulos C, Flevari P, Terpos E, et al. The Growth Differentiation Factor-15 (GDF-15) levels are increased in patients with compound heterozygous sickle cell and beta-thalassemia (HbS/ $\beta$ thal), correlate with markers of hemolysis, iron burden, coagulation, endothelial dysfunction and pulmonary hypertension. Blood Cells Mol Dis. 2019 Jul;77:137-41.

21 Yawn BP, Buchanan GR, Afenyi-Annan AN, Ballas SK, Hassell KL, James AH, et al. Management of sickle cell disease: summary of the 2014 evidence-based report by expert panel members. JAMA. 2014 Sep;312(10): 1033-48.

22 Turpin M, Chantalat-Auger C, Parent F, Driss F, Lionnet F, Habibi A, et al. Chronic blood exchange transfusions in the management of pre-capillary pulmonary hypertension complicating sickle cell disease. Eur Respir J. 2018 Oct:52(4): 1800272. 
23 Charache S, Terrin ML, Moore RD, Dover GJ, Barton FB, Eckert SV, et al. Effect of hydroxyurea on the frequency of painful crises in sickle cell anemia. Investigators of the Multicenter Study of Hydroxyurea in sickle cell anemia. N Engl J Med. 1995 May;332(20): 1317-22.

24 Steinberg MH, McCarthy WF, Castro O, Ballas SK, Armstrong FD, Smith W, et al. The risks and benefits of long-term use of hydroxyurea in sickle cell anemia: a 17.5 year follow-up. Am J Hematol. 2010 Jun;85(6): 403-8.

25 Estcourt LJ, Fortin PM, Hopewell S, Trivella M, Hambleton IR, Cho G. Regular long-term red blood cell transfusions for managing chronic chest complications in sickle cell disease. Cochrane Database Syst Rev. 2016 May(5):CD008360.
26 Chou ST, Alsawas M, Fasano RM, Field JJ, Hendrickson JE, Howard J, et al. American Society of Hematology 2020 guidelines for sickle cell disease: transfusion support. Blood Adv. 2020 Jan;4(2):327-55.

27 Machado RF, Martyr S, Kato GJ, Barst RJ, Anthi A, Robinson MR, et al. Sildenafil therapy in patients with sickle cell disease and pulmonary hypertension. Br J Haematol. 2005 Aug; 130(3):445-53.

28 Minniti CP, Machado RF, Coles WA, Sachdev V, Gladwin MT, Kato GJ. Endothelin receptor antagonists for pulmonary hypertension in adult patients with sickle cell disease. $\mathrm{Br}$ J Haematol. 2009 Dec;147(5):737-43.

29 Gladwin MT, Sachdev V, Jison ML, Shizukuda Y, Plehn JF, Minter K, et al. Pulmonary hypertension as a risk factor for death in patients with sickle cell disease. N Engl J Med. 2004 Feb;350(9):886-95.
30 Mehari A, Alam S, Tian X, Cuttica MJ, Barnett CF, Miles G, et al. Hemodynamic predictors of mortality in adults with sickle cell disease. Am J Respir Crit Care Med. 2013 Apr; 187(8):840-7.

31 Nouraie M, Darbari DS, Rana S, Minniti CP Castro OL, Luchtman-Jones L, et al. Tricuspid regurgitation velocity and other biomarkers of mortality in children, adolescents and young adults with sickle cell disease in the United States: the PUSH study. Am J Hematol. 2020 Jul;95(7):766-74.

32 Tsitsikas DA, Badle S, Hall R, Meenan J, Bello-Sanyaolu O, Orebayo F, et al. Automated Red Cell Exchange in the Management of Sickle Cell Disease. J Clin Med. 2021 Feb; 10(4):767. 